Journal of Physical Science, Vol. 28(2), 31-56, 2017

\title{
Synthesis, Crystal Growth, Vibrational Spectral Analysis, Optical Thermal and Antimicrobial Properties of Guanidinium Oxalate Monohydrate Single Crystal
}

\author{
T. Uma Devi, ${ }^{1 *}$ A. Josephine Prabha,${ }^{2}$ R. Meenakshi, ${ }^{3}$ G. Kalpana ${ }^{1}$ and C. Surendra Dilip ${ }^{4}$ \\ ${ }^{1}$ Department of Physics, Government Arts College for Women, Pudukkottai, India \\ ${ }^{2}$ Department of Physics, Bishop Heber College, Tiruchirappalli 620 017, India \\ ${ }^{3}$ Department of Physics, Cauvery College for Women, Tiruchirappalli, India \\ ${ }^{4}$ Department of Chemistry, BIT Campus, Anna University, Tiruchirappalli, India
}

*Corresponding author: kavin_shri@yahoo.co.in

Published online: 15 August 2017

To cite this article: Uma Devi, T. et al. (2017). Synthesis, crystal growth, vibrational spectral analysis, optical thermal and antimicrobial properties of guanidinium oxalate monohydrate single crystal. J. Phys. Sci., 28(2), 31-57, https://doi.org/10.21315/jps2017.28.2.3

To link to this article: https://doi.org/10.21315/jps2017.28.2.3

\begin{abstract}
Crystals of guanidinium oxalate monohydrate (GUOM), a salt of a functional guanidine derivative, crystallising with the space group of $P 2_{1} / c$, is synthesised and characterised by single-crystal XRD, NMR, UV-Vis and vibrational spectroscopy. The assignment of spectral bands is carried out in terms of the fundamental modes of vibration of the guanidinium cation and oxalate anion. Thermal analysis (TG/DTA) indicates that the compound is thermally robust. GUOM also exhibits antimicrobial activity against a few microorganisms.
\end{abstract}

Keywords: Single crystal, solution method, XRD, FTIR, NLO, TG/DTA

\section{INTRODUCTION}

Guanidine salts possess fascinating properties and have drawn much attention as phase transition dielectric materials, in addition to being well known for their relevance in memory storage. ${ }^{1}$ The structures of the guanidinium salts of aromatic and heteroaromatic polyfunctional carboxylic acids are of interest because of the capacity of the guanidinium cation to make stable supramolecular framework structures through hydrogen-bonding associations, largely cyclic, such as those originating in the structures of guanidinium carbonate. ${ }^{2}$ Due to the strong base nature of guanidine, it can readily undergo protonation to generate a resonance- 
stabilised guanidinium cation. ${ }^{2,3}$ The guanidinium ion, $\mathrm{C}^{+}\left(\mathrm{NH}_{2}\right)_{3}$, is a moderately simple chemical variety and has received much attention from spectroscopists. ${ }^{3-7}$

Guanidine with its planar conformation and the six potential H-donors being used in various supramolecular recognition processes has spanned the spectrum of organic, biological and medicinal chemistry, with special interest motivated by their potential applications in nonlinear optics. ${ }^{8-11}$ The examination of literature data on the simple guanidinium salts shows that guanidinium 4-aminobenzoate, guanidinium perchlorate, guanidinium sulfonates, and guanidinium p-nitrophenolate, etc., exhibit nonlinear optical mechanism. ${ }^{12-15}$

The structures of the amine oxalates show strong hydrogen bond interactions typical of non-covalent solids involving the oxalate and amine moieties. The structurally significant hydrogen bonds arise mainly from $\mathrm{N}-\mathrm{H} \cdots \mathrm{O}$ and $\mathrm{O}-\mathrm{H} \cdots \mathrm{O}$ interactions. In most of the amine oxalates one of the carboxyl groups transfers a proton to the amino nitrogen, leaving the other carboxyl group free, to form a linear hydrogen bonded chain. ${ }^{16}$ Studies on the oxalate compounds are interesting due to their importance in medical field, and their occurrence in renal and urinary calculi. ${ }^{17}$

Guanidine may be readily protonated by most aliphatic diprotic acids such as oxalic acid. The crystal structure of guanidinium oxalate monohydrate (GUOM) $\mathrm{C}\left(\mathrm{NH}_{2}\right)_{3} \mathrm{HC}_{2} \mathrm{O}_{4} \cdot \mathrm{H}_{2} \mathrm{O}$ is reported by Adams. ${ }^{18}$ It belongs to monoclinic crystal system with a centrosymmetric space group $P_{21} / n$ having four molecules per unit cell. Investigation on hydrogen-bond network in GUOM carried out by singlecrystal diffraction study at room temperature indicates the existence of strong hydrogen bond interactions typical of non-covalent solids involving the oxalate and amine moieties. ${ }^{19}$ In the present study, we report for the first time nuclear magnetic resonance (NMR) and Fourier transform infrared (FTIR) spectra of GUOM using theoretical and experimental techniques. Detailed vibrational spectral investigations of GUOM molecule using scaled quantum mechanical (SQM) force field technique based on density functional theory (DFT) calculations is performed. From natural bond orbital analysis (NBO), electron charge transfer through intermolecular hydrogen bonding is explained. Additionally, optical, thermal and antimicrobial properties of GUOM have also been discussed. 


\section{EXPERIMENTAL}

\subsection{Synthesis and Crystal Growth}

GUOM is synthesised by the reaction between guanidinium carbonate (Merck) and oxalic acid (Loba Chemie) taken in stoichiometric proportions. The reactants are thoroughly dissolved in double distilled water by stirring well using a temperature controlled magnetic stirrer to yield a homogeneous solution. This solution being allowed to evaporate at room temperature, yielded transparent crystalline salt of GUOM. Purification of the synthesised salt was done by repeated recrystallisation process. The chemical structure of GUOM is shown in Figure 1.

Further, about $200 \mathrm{ml}$ saturated solution of GUOM is prepared at $35^{\circ} \mathrm{C}$ from recrystallised salt and filtered with microfilters. This solution is taken in a beaker and placed in a constant temperature bath having an accuracy of $\pm 0.01^{\circ} \mathrm{C}$. Single crystal of GUOM is grown by the slow cooling method by reducing the temperature from $35^{\circ} \mathrm{C}$ at the rate of $0.1^{\circ} \mathrm{C}$ per day. Well-developed crystal of size $10 \times 5 \times 5 \mathrm{~mm}^{3}$ is harvested in a growth period of 15 days and is shown in Figure 2 .

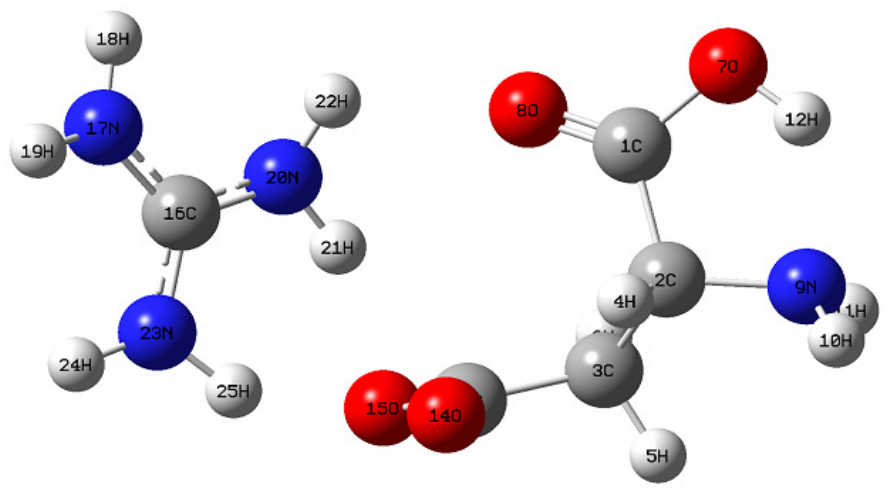

Figure 1: Chemical structure of GUOM. 


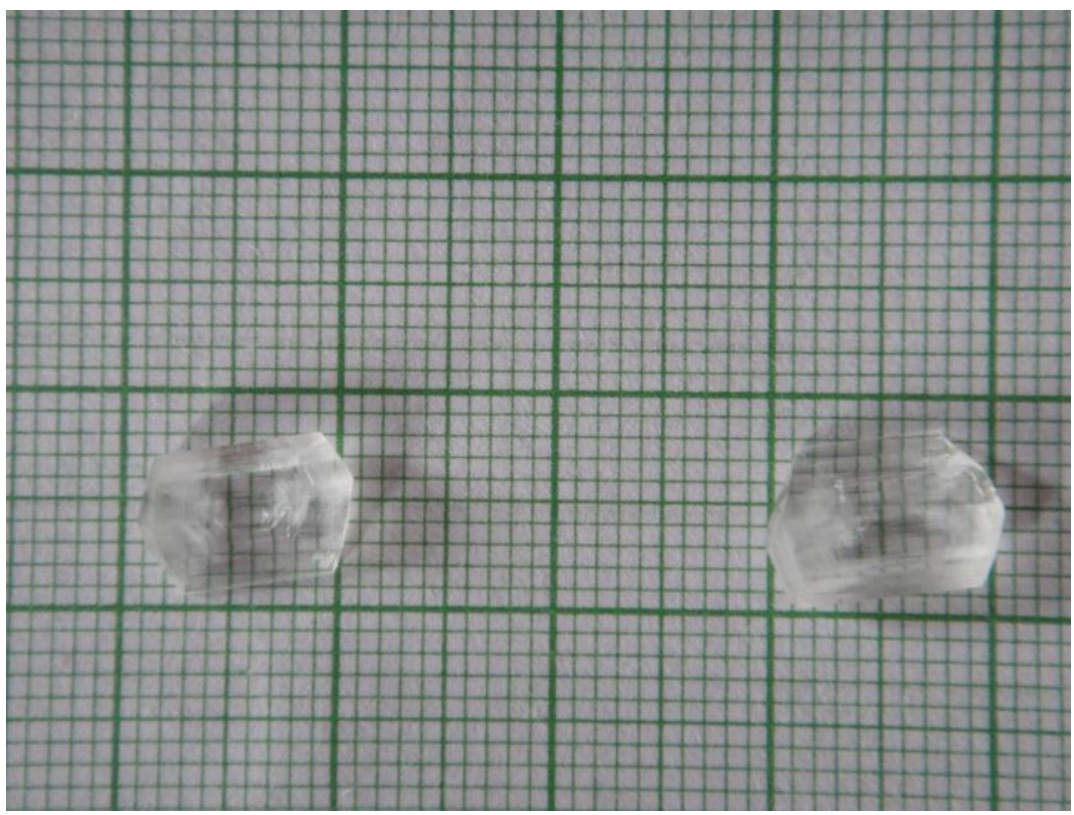

Figure 2: As-grown GUOM single crystal.

\subsection{Characterisation and Computation}

Single crystal X-ray diffraction data are collected for a transparent well shaped single crystal of GUOM using Enraf Nonius-CAD4 single crystal X-ray diffractometer.

In order to study the optical absorption characteristics of the grown crystal UVVis-NIR spectrum is recorded in the wavelength range of 200-1000 nm using spectrophotometer (Lambda model 35). The vibrational analysis of GUOM is carried out based on the scaled quantum mechanical (SQM) force field methodology. The first hyperpolarisability of this molecular system is calculated using B3LYP/6$31 \mathrm{G}$ method, based on the finite-field approach.

\section{STRUCTURAL ANALYSIS}

The grown crystals are highly transparent and non-hygroscopic. The morphology of GUOM establishes well-developed faces. 


\subsection{X-Ray Diffraction Studies}

Single crystal X-ray diffraction study shows that GUOM crystallises in the monoclinic crystal system and the corresponding data are listed in Table 1. The optimised geometrical parameters are given in Table 2. It is evident that there is good agreement between the theoretical and the reported experimental values. ${ }^{18}$

Table 1: Comparison of unit cell parameters of GUOM.

\begin{tabular}{llllll}
\hline S.No. & $\mathrm{a}(\AA)$ & $\mathrm{b}(\AA)$ & $\mathrm{c}(\AA)$ & $\beta\left(^{\circ}\right)$ & Reference \\
\hline 1. & 6.45 & 9.88 & 10.17 & 103.67 & Present work \\
2. & 6.70 & 10.55 & 10.21 & 103.8 & {$[11]$} \\
\hline
\end{tabular}

Table 2: Experimental and theoretical geometric data for GUOM at B3LYP/6-311G level.

\begin{tabular}{llllll}
\hline \multicolumn{2}{l}{ Bond length $(\AA)$} & $\mathrm{XRD}^{18}$ & \multicolumn{2}{c}{ Bond angles $\left(^{\circ}\right)$} & $\mathrm{XRD}^{18}$ \\
\hline C4-C7 & 1.5338 & 1.53 & O5-C4-O6 & 128.7337 & 126.3 \\
C4-O5 & 1.2436 & 1.232 & C4-C7-O8 & 112.3192 & 115.4 \\
C4-O6 & 1.2466 & 1.263 & C4-C7-O9 & 124.9861 & 118.2 \\
C7-O8 & 1.3498 & 1.325 & O8-C7-O9 & 122.6946 & 122.9 \\
C7-O9 & 1.2004 & 1.208 & C7-C4-O5 & 117.2246 & 114.6 \\
C11-N18 & 1.3158 & 1.325 & C7-C4-O6 & 114.0417 & 122.5 \\
C11-N19 & 1.3118 & 1.312 & N18-C11-N20 & 121.6426 & 121.1 \\
C11-N20 & 1.3121 & 1.330 & N18-C11-N19 & 119.181 & 118.8 \\
N18-H12 & 0.9973 & 0.94 & N19-C11-N20 & 119.1758 & 120 \\
N18- H13 & 1.0567 & 1.03 & & & \\
N19-H14 & 0.9977 & 1 & & & \\
N19-H15 & 1.0473 & 1.09 & & & \\
N20-H16 & 0.9954 & 0.85 & & & \\
N20-H17 & 0.6957 & 0.65 & & & \\
O8-H10 & 0.9684 & 0.97 & & & \\
\hline
\end{tabular}

\subsection{Vibrational Analysis}

The vibrational analysis of GUOM is carried out based on the scaled quantum mechanical (SQM) force field methodology. The recorded FTIR spectrum of GUOM is shown in Figure 3. The observed and calculated frequencies of GUOM are reported in Table 3 . OH vibrations are commonly observed in the region $3200-3600 \mathrm{~cm}^{-1} \cdot{ }^{20}$ There is a moderately strong IR peak at $3148 \mathrm{~cm}^{-1}$ for $\mathrm{OH}$ 
stretching. In the theoretical IR spectra, a peak at $3060 \mathrm{~cm}^{-1}$ is attributed to the $\mathrm{OH}$ group. The $\mathrm{OH}$ in-plane bending and out of plane bending vibrations are identified at 1389 and $1176 \mathrm{~cm}^{-1}$ in FTIR spectrum. The theoretical wavenumbers corresponding to these bending vibrations are observed at 1394 and $1172 \mathrm{~cm}^{-1}$ by $\mathrm{HF} / 6-311++\mathrm{G}$.

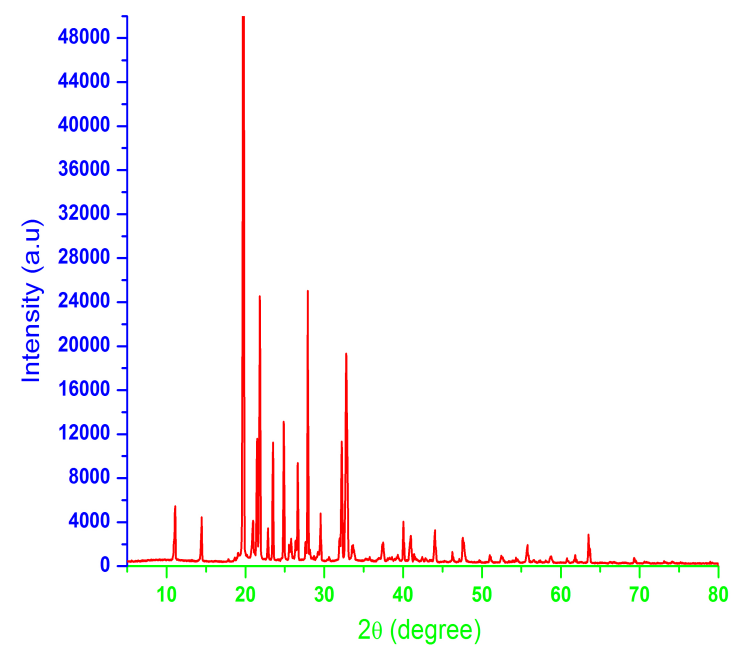

Figure 3: FTIR spectrum of GUOM.

Table 3: Observed and calculated wave numbers $\left(\mathrm{cm}^{-1}\right)$ for $\mathrm{GUOM}$ at $\mathrm{HF} / 6-311++\mathrm{G}$ level.

\begin{tabular}{|c|c|c|}
\hline \multicolumn{2}{|c|}{ Wavenumbers $\left(\mathrm{cm}^{-1}\right)$} & \multirow{2}{*}{ Assignment } \\
\hline FTIR & Calculated & \\
\hline 3148 & 3060 & $v \mathrm{OH}$ \\
\hline 2996 & 2964 & $v \mathrm{NH}_{2}$ ass \\
\hline 2442 & 2378 & $v \mathrm{CO}_{2 \mathrm{ass}}$ \\
\hline 1671 & 1674 & $v \mathrm{CC}$ \\
\hline 1578 & 1550 & $v \mathrm{CO}_{2 \mathrm{ss}}$ \\
\hline 1389 & 1394 & $\delta \mathrm{OH}$ \\
\hline 1176 & 1172 & $v \mathrm{CN}$ \\
\hline 1007 & 1059 & $\omega \mathrm{OH}$ \\
\hline 881 & 887 & $\omega \mathrm{CC}$ \\
\hline 540 & 570 & $\mathrm{CN}$ bend \\
\hline
\end{tabular}


The N-H stretching of amines are in the region $3300-3000 \mathrm{~cm}^{-1}$. These bands are weaker and sharper than those of the alcohol $\mathrm{O}-\mathrm{H}$ stretching which appear in the same region. There are two bands in this region, the asymmetrical $\mathrm{N}-\mathrm{H}$ stretch and the symmetrical $\mathrm{N}-\mathrm{H}$ stretch. The asymmetrical $\mathrm{N}-\mathrm{H}$ stretch is identified at $2996 \mathrm{~cm}^{-1}$ in FTIR spectrum. It is also validated by theoretical wave number calculated by HF/6-311++G as $2964 \mathrm{~cm}^{-1}$. In general, the $\mathrm{C}-\mathrm{N}$ stretching vibration is observed as medium or weak bands in the region $1250-1020 \mathrm{~cm}^{-1}$. Accordingly, in this title compound, the band observed at $1176 \mathrm{~cm}^{-1}$ is assigned to $\mathrm{C}-\mathrm{N}$ stretching vibration of guanidinium. The presence of $\mathrm{CO}_{2}$ in the title compound is identified by asymmetric stretching and symmetric stretching at 2442 and $1578 \mathrm{~cm}^{-1}$, respectively.

\subsection{First Hyperpolarisability}

The electronic and vibrational contributions to the first hyperpolarisabilities have been studied theoretically for many organic and inorganic systems. The values of the first hyperpolarisability are found to be quite large for the so-called push-pull molecules, i.e., p-conjugated molecules with the electron donating and the electron withdrawing substituents attached to a ring, compared to the mono substituted systems. ${ }^{21}$ This type of functionalisation of organic materials is meant for the purpose of maximising NLO properties.

The first hyperpolarisability $(\beta)$ of GUOM is calculated using B3LYP/6-311G method, based on the finite-field approach, which is a third rank tensor that can be described by $3 \times 3 \times 3$ matrices. It is well known that in the presence of an applied electric field, the energy of a system is a function of the electric field. The components of the matrix are defined as the coefficients in the Taylor series expansion of the energy in the presence of external electric field. When the external electric field is weak and homogeneous, this expansion becomes:

$\mathrm{E}=\mathrm{E}^{0}-\mu_{\alpha} \mathrm{F}_{\alpha}-\frac{1}{2} \alpha_{\alpha \beta} \mathrm{F}_{\alpha} \mathrm{F}_{\beta-} \frac{1}{6} \beta_{\alpha \beta \gamma} \mathrm{F}_{\alpha} \mathrm{F}_{\beta} \mathrm{F}_{\gamma}+.$.

where $\mathrm{E}^{0}$ is the energy of the unperturbed molecule, $\mathrm{F}_{\alpha}$ is the field at the origin and $\mu_{\alpha,}, \alpha_{\alpha \beta}$ and $\beta_{\alpha \beta \gamma}$ are the components of dipole moment, polarisability and the first order hyperpolarisabilities, respectively. The total static dipole moment $\mu$ and the mean first hyperpolarisability $(\beta)$ using the $\mathrm{x}, \mathrm{y}, \mathrm{z}$ components are defined as:

$$
\begin{aligned}
& \mu=\left(\mu_{\mathrm{x}}^{2}+\mu_{\mathrm{y}}^{2}+\mu_{\mathrm{z}}^{2}\right)^{1 / 2} \\
& \beta=\left(\beta_{\mathrm{x}}^{2}+\beta_{\mathrm{y}}^{2}+\beta_{\mathrm{z}}^{2}\right)^{1 / 2}
\end{aligned}
$$


where

$\beta_{\mathrm{x}}=\beta_{\mathrm{xxx}}+\beta_{\mathrm{xyy}}+\beta_{\mathrm{xzz}}$

$\beta_{\mathrm{y}}=\beta_{\mathrm{yyy}}+\beta_{\mathrm{xxy}}+\beta_{\mathrm{yzz}}$

$\beta_{\mathrm{z}}=\beta_{\mathrm{zzz}}+\beta_{\mathrm{xxz}}+\beta_{\mathrm{yyz}}$

Since the value of hyperpolarisability $(\beta)$ of the Gaussian $09 \mathrm{~W}$ output is reported in atomic units (a.u.), the calculated values have been converted into electrostatic units $(\mathrm{esu})\left(\beta\right.$ : 1 a.u. $\left.=8.639 \times 10^{-33} \mathrm{esu}\right)$. The first hyperpolarisability of GUOM is $0.7818 \times 10^{-30} \mathrm{esu}$, as shown in Table 4 . The first hyperpolarisability of title compound is two times greater than those of urea ( $\mu$ and $\beta$ of urea are 1.3732 Debye and $0.3728 \times 10^{-30}$ esu obtained by HF/6-311G(d,p) method).

Table 4: The first hyperpolarisability of GUOM

\begin{tabular}{ll}
\hline Parameters & Values (a.u) \\
\hline$\beta_{\mathrm{xxx}}$ & -40.9561348 \\
$\beta_{\mathrm{xxy}}$ & 82.9133381 \\
$\beta_{\mathrm{xyy}}$ & -47.0707119 \\
$\beta_{\mathrm{yyy}}$ & -101.761438 \\
$\beta_{\mathrm{xxz}}$ & -25.590286 \\
$\beta_{\mathrm{xyz}}$ & 13.8706948 \\
$\beta_{\mathrm{yyz}}$ & 22.1971841 \\
$\beta_{\mathrm{xzz}}$ & -2.4561711 \\
$\beta_{\mathrm{yzz}}$ & 16.5641459 \\
$\beta_{\mathrm{zzz}}$ & 10.5619162 \\
$\beta$ & $0.7818 \times 10^{-30} \mathrm{esu}$ \\
\hline
\end{tabular}

\subsection{HOMO-LUMO analysis}

The interaction of the molecule with other molecules can be determined from the Highest Occupied Molecular Orbitals (HOMO) and the Lowest Unoccupied Molecular Orbitals (LUMO). The difference in the energies of these levels gives the energy gap from which the chemical reactivity and the kinetics of the molecule can be studied. HOMO and LUMO plots of GUOM and the energies of these orbitals in the gas phase are given in Figure 4. The HOMO is located on oxalate as well as on the guanidinium group, with only minor population. The population of LUMO shows that the charge transfer is taking place from guanidinium to 
oxalate group. According to molecular orbital theory, HOMO and LUMO are two important factors which are influencing the bioactivity. The DOS spectrum of GUOM is shown in Figure 5 which also supports the energy gap of GUOM.

HOMO energy $=-4.2504 \mathrm{eV}$

LUMO energy $=-9.1864 \mathrm{eV}$

HOMO-LUMO energy gap, $\mathrm{E}_{\mathrm{g}}=4.936 \mathrm{eV}$
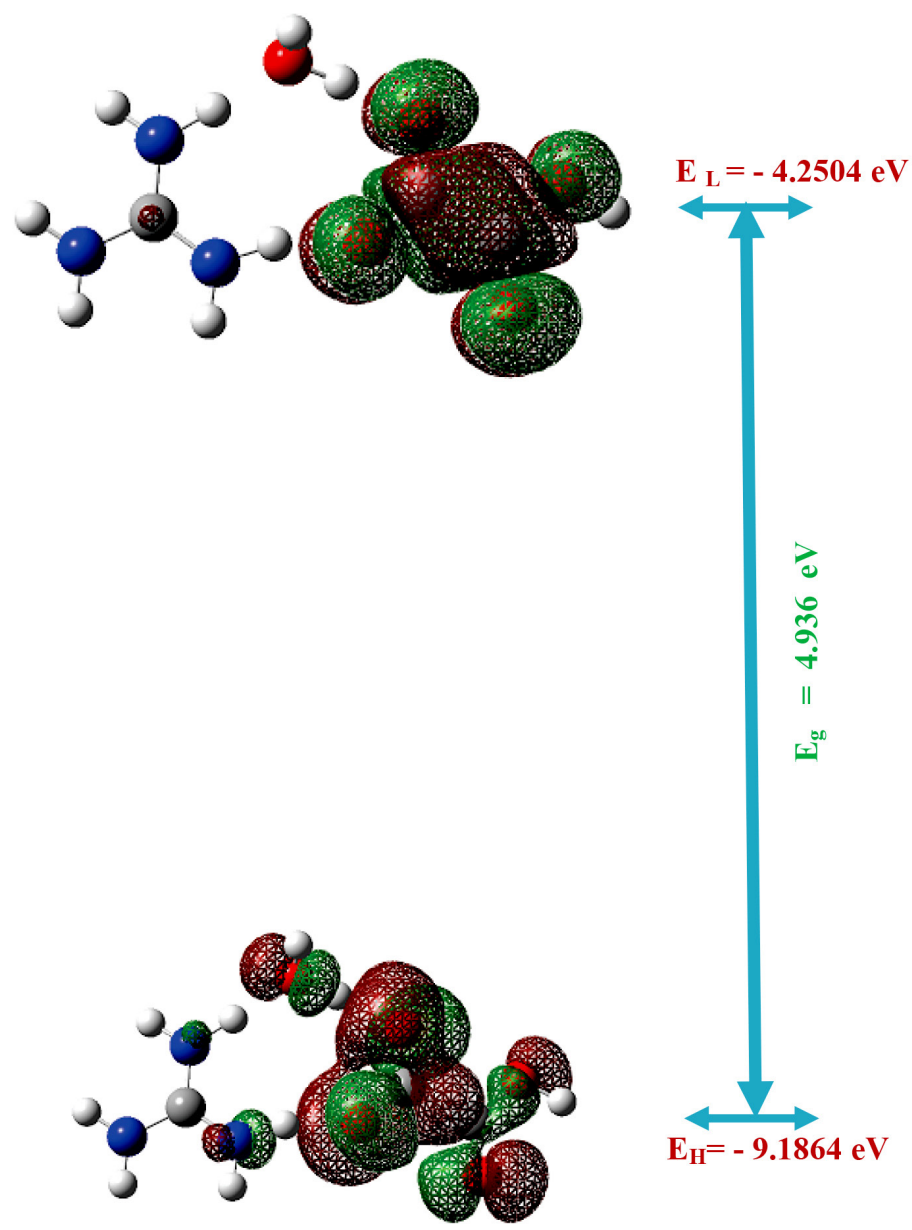

$E_{H}=-9.1864 \mathrm{eV}$

Figure 4: HOMO and LUMO molecular orbitals of GUOM. 


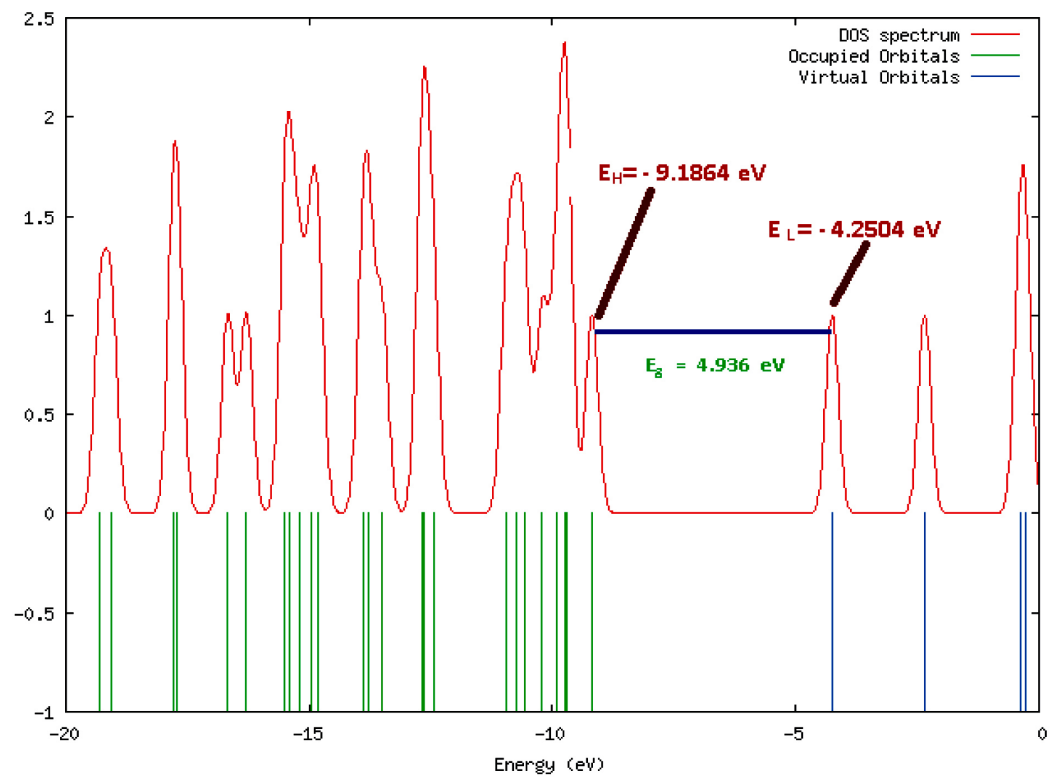

Figure 5: DOS spectrum of GUOM.

\subsection{Global Reactivity Descriptors}

The estimation of the reactivity of chemical species is one of the main purposes of theoretical chemistry and a lot of work has been done in this line. Density functional theory has been successful in giving theoretical background of accepted qualitative chemical concepts. In this framework, several reactivity descriptors have been projected and are used to analyse chemical reactivity and site selectivity. Hardness, global softness, electro negativity and polarisability are the global reactivity descriptors widely used to understand the global nature of molecules in terms of their stability and it is possible to gain knowledge about the reactivity of molecules.

From Koopman's theorem, the ionisation potential (IP) and electron affinity (EA) are the eigen values of HOMO and LUMO with change of sign. ${ }^{22}$

$$
\mathrm{IP} \approx-\mathrm{E}_{\mathrm{HOMO}} \text { and } \mathrm{E}_{\mathrm{A}} \approx-\mathrm{E}_{\mathrm{LUMO}}
$$

Several global chemical reactivity descriptors of molecules such as hardness (h), chemical potential (m), softness (s), electronegativity (c) and elctrophilicity index (w) are calculated based on the density functional theory (DFT). The global hardness $(\mathrm{h})$ and chemical potential $(\mathrm{m})$ are defined as the second and 
first derivatives of the energy (E) with respect to the number of electrons $(\mathrm{N})$ at constant external potential, $\mathrm{V}(\bar{r})$.

$\eta=\frac{1}{2}\left(\frac{\partial^{2} E}{\partial \mathrm{N}^{2}}\right)_{\mathrm{v}(\bar{r})}$ and $\mu=\left(\frac{\partial E}{\partial \mathrm{N}}\right)_{\mathrm{v}(\bar{r})}$

In Equation 7, $\mathrm{E}$ and $\mathrm{V}(\bar{r})$ are electronic energy and external potential of an N-electron system, respectively. Softness is a property of molecule which measures the extent of chemical reactivity. It is the reciprocal of hardness. The electronegativity is defined as the negative of the electronic chemical potential.

$\mathrm{S}=\frac{1}{2 \eta}$ and $\chi=-\left(\frac{\partial E}{\partial \mathrm{N}}\right)_{\mathrm{v}(\bar{r})}$

Using Koopman's theorem for closed shell molecules $\eta, \mu$ and $\chi$ can be redefined as:

$$
\begin{aligned}
& \eta \approx \frac{1}{2}(\mathrm{IP}-\mathrm{EA}) \approx \frac{1}{2}\left(\mathrm{E}_{\mathrm{LUMO}}-\mathrm{E}_{\text {номо }}\right) \\
& \mu \approx-\frac{1}{2}(\mathrm{IP}+\mathrm{EA}) \approx \frac{1}{2}\left(\mathrm{E}_{\text {номо }}+\mathrm{E}_{\mathrm{LUMO}}\right) \\
& \chi=\frac{\mathrm{I}+\mathrm{A}}{2}
\end{aligned}
$$

The concept of electrophilicity viewed as a reactivity index was introduced by Parr et al. ${ }^{24}$ It is based on a second order expansion of the electronic energy with respect to the charge transfer $\Delta \mathrm{N}$ at fixed geometry. This index measures the stabilisation in energy when the system acquires an additional electronic charge $\Delta \mathrm{N}$ from the environment and is defined by the following simple and more familiar form in terms of the electronic chemical potential $(\mu)$ and the chemical hardness $(\eta) .{ }^{24}$ Electrophilicity is a useful structural depictor of reactivity and is frequently used in the analysis of the chemical reactivity of molecules.

$$
\omega=\frac{\mu^{2}}{2 \eta}
$$

Maximum amount of electronic charge that an electrophilic system may accept is given by the following equation: ${ }^{24}$

$\Delta \mathrm{N}_{\max }=-\frac{\mu}{\eta}$

The maximum charge transfer $\Delta \mathrm{N}_{\max }$ in the direction of the electrophile is predicted using Equation 13. Thus, while the quantity defined by Equation 13 describes the tendency of the molecule to acquire additional electronic charge from the 
environment, the quantity defined in Equation 12 describes the charge capacity of the molecule. All the calculated DFT reactivity descriptors are summarised in Table 5.

Table 5: The theoretical reactivity descriptors of GUOM by B3LYP/6-311G method.

\begin{tabular}{ll}
\hline Parameters & Values $(\mathrm{eV})$ \\
\hline HOMO energy $\left(\mathrm{E}_{\text {Hомо }}\right)$ & -9.1864 \\
LUMO energy $\left(\mathrm{E}_{\text {LUMO }}\right)$ & -4.2504 \\
Energy gap $\left(\mathrm{E}_{\mathrm{g}}\right)$ & 4.936 \\
Ionisation potential $(\mathrm{IP})$ & 9.1864 \\
Electron affinity $(\mathrm{EA})$ & 4.2504 \\
Hardness $(\mathrm{\eta})$ & 2.468 \\
Softness $(\mathrm{s})$ & 0.2025 \\
Chemical potential $(\mu)$ & -6.7184 \\
Electronegativity $(\chi)$ & 6.7184 \\
Electrophilicity index $(\omega)$ & 9.1444 \\
Charge transfer $\left(\Delta \mathrm{N}_{\max }\right)$ & 2.7222 \\
\hline
\end{tabular}

\subsection{Natural Bond Orbital Analysis}

The interpretation of wavefunctions of atoms can be done chemically using Natural Bond Orbital Analysis (NBO). The presence of hydrogen bonding and the other intra or intermolecular charge transfer taking place in the molecule can be analysed. Existence of intermolecular hydrogen bonds $\mathrm{O}-\mathrm{C}-\mathrm{C}$ and $\mathrm{O}-\mathrm{C}-\mathrm{O}$ can be confirmed from the interaction between $\mathrm{n}_{2} \mathrm{O} 9-\sigma^{*}(\mathrm{C} 4-\mathrm{C} 7)$ and $\mathrm{n}_{3}(\mathrm{O} 6)$ $\sigma^{*}(\mathrm{C} 4-\mathrm{O} 5)$ with a stabilisation energy of $26.89 \mathrm{kcal} / \mathrm{mol}$ and $204.91 \mathrm{kcal} / \mathrm{mol}$, respectively. Intramolecular charge transfer (ICT) which stabilises the system is formed by the overlap of $n_{2}(\mathrm{O} 6) \rightarrow \sigma^{*}(\mathrm{H} 15-\mathrm{N} 19)$ with the stabilisation energy of $60.52 \mathrm{kcal} / \mathrm{mol}$. The estimated values are listed in Table 6 .

Table 6: NBO analysis of Second Order Perturbation Theory of Fock Matrix of GUOM at B3LYP/6-311G level.

\begin{tabular}{lccll}
\hline Donor (i) & Acceptor (j) & $\begin{array}{l}\mathrm{E}^{(2)} \\
\mathrm{kcal} / \mathrm{mol}\end{array}$ & $\begin{array}{l}\mathrm{E}(\mathrm{j})-\mathrm{E}(\mathrm{i}) \\
\text { a.u }\end{array}$ & $\begin{array}{l}\mathrm{F}(\mathrm{i}, \mathrm{j}) \\
\text { a.u }\end{array}$ \\
\hline \multicolumn{7}{l}{ Inter molecular interactions in oxalate moiety } \\
\hline $\mathrm{n}_{2}\left(\mathrm{O}_{5}\right)$ & $\sigma^{*}(\mathrm{C} 4-\mathrm{C} 7)$ & 23.18 & 1.09 & 0.144 \\
$\mathrm{n}_{1}\left(\mathrm{O}_{6}\right)$ & $\sigma^{*}(\mathrm{C} 4-\mathrm{O} 5)$ & 14.19 & 1.57 & 0.134 \\
\hline \multicolumn{7}{l}{} & & (continued on next page)
\end{tabular}


Table 6: (continued)

\begin{tabular}{lccll}
\hline Donor $(\mathrm{i})$ & Acceptor $(\mathrm{j})$ & $\begin{array}{l}\mathrm{E}^{(2)} \\
\mathrm{kcal} / \mathrm{mol}\end{array}$ & $\begin{array}{l}\mathrm{E}(\mathrm{j})-\mathrm{E}(\mathrm{i}) \\
\text { a.u }\end{array}$ & $\begin{array}{l}\mathrm{F}(\mathrm{i}, \mathrm{j}) \\
\text { a.u }\end{array}$ \\
\hline \multicolumn{5}{l}{ Inter molecular interactions in oxalate } \\
\hline $\mathrm{n}_{2}\left(\mathrm{O}_{6}\right)$ & $\sigma^{*}(\mathrm{C} 4-\mathrm{C} 7)$ & 19.66 & 1.13 & 0.134 \\
$\mathrm{n}_{3}\left(\mathrm{O}_{6}\right)$ & $\sigma^{*}(\mathrm{C} 4-\mathrm{O} 5)$ & 204.91 & 0.46 & 0.275 \\
$\mathrm{n}_{2}\left(\mathrm{O}_{8}\right)$ & $\sigma^{*}(\mathrm{C} 7-\mathrm{O} 9)$ & 70.94 & 0.66 & 0.193 \\
$\mathrm{n}_{2}\left(\mathrm{O}_{9}\right)$ & $\sigma^{*}(\mathrm{C} 4-\mathrm{C} 7)$ & 26.89 & 1.03 & 0.149 \\
$\mathrm{n}_{2}\left(\mathrm{O}_{9}\right)$ & $\sigma^{*}(\mathrm{C} 7-\mathrm{O} 8)$ & 50.39 & 1.01 & 0.203 \\
\hline \multicolumn{5}{l}{ Intra molecular interactions between guanidinium and oxalate moieties } \\
\hline $\mathrm{n}_{2}(\mathrm{O} 6)$ & $\sigma^{*}(\mathrm{H} 15-\mathrm{N} 19)$ & 60.52 & 1.18 \\
$\mathrm{n}_{1}(\mathrm{O} 6)$ & $\sigma^{*}(\mathrm{H} 15-\mathrm{N} 19$ & 17.78 & 1.41 & 0.241 \\
\hline
\end{tabular}

\subsection{Molecular Electrostatic Potential (MEP) analysis}

In order to grasp the molecular interactions, the molecular electrostatic potential (MEP) is used. The electrostatic potential is considered predictive of chemical reactivity because regions of negative potential are expected to be sites of protonation and nucleophilic attack, while regions of positive potential may indicate electrophilic sites. Figure 6 shows the theoretical map of the electrostatic potential distribution in the plane of the base ring. B3LYP level of theory at $6-311++\mathrm{G}$ is used to describe the theoretical electrostatic potential map. The extension of the positive electrostatic potential around the guanidinium and the regions of negative electrostatic potential around oxalate group show the nature of the intramolecular charge transfer. The electron density contour of GUOM is also shown in Figure 7.

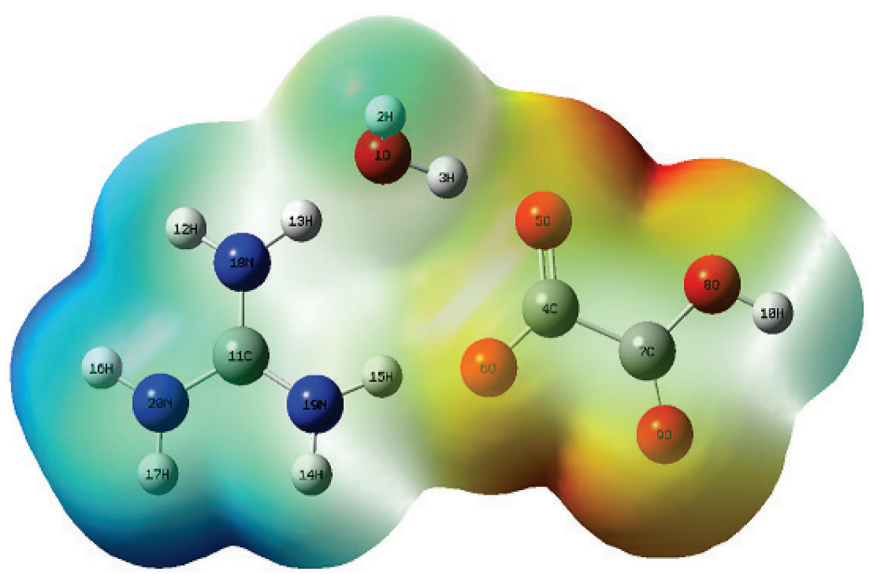

Figure 6: MEP surfaces of GUOM. 


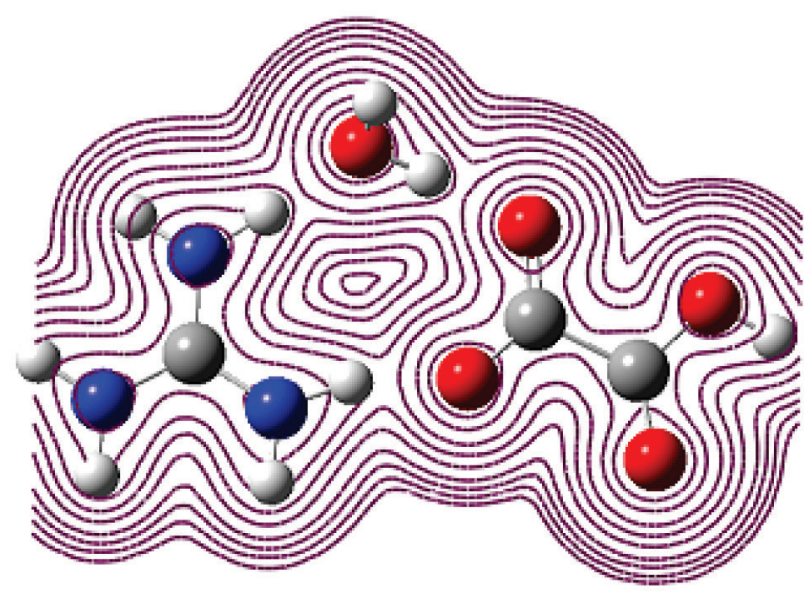

Figure 7: Electron density of GUOM.

\subsection{NMR Spectral studies}

The ${ }^{1} \mathrm{H}$ NMR spectrum of GUOM is shown in Figure 8 along with the theoretical spectrum. The signals which appear in range of $\delta 7.17-7.27 \mathrm{ppm}$ have been assigned to the six amine proton. The two proton signals at $\delta 7.57$ and $7.58 \mathrm{ppm}$ indicate the presence of $\mathrm{H}_{2} \mathrm{O}$. The ${ }^{13} \mathrm{C}$ NMR spectrum of GUOM is shown in Figure 9 along with the theoretical spectrum. The appearance of two signals at $\delta 168.08$ and $173.09 \mathrm{ppm}$ confirms the presence of oxalate functional group. The presence of guanidinium carbon chemical shift is identified at $157 \mathrm{ppm}$. 


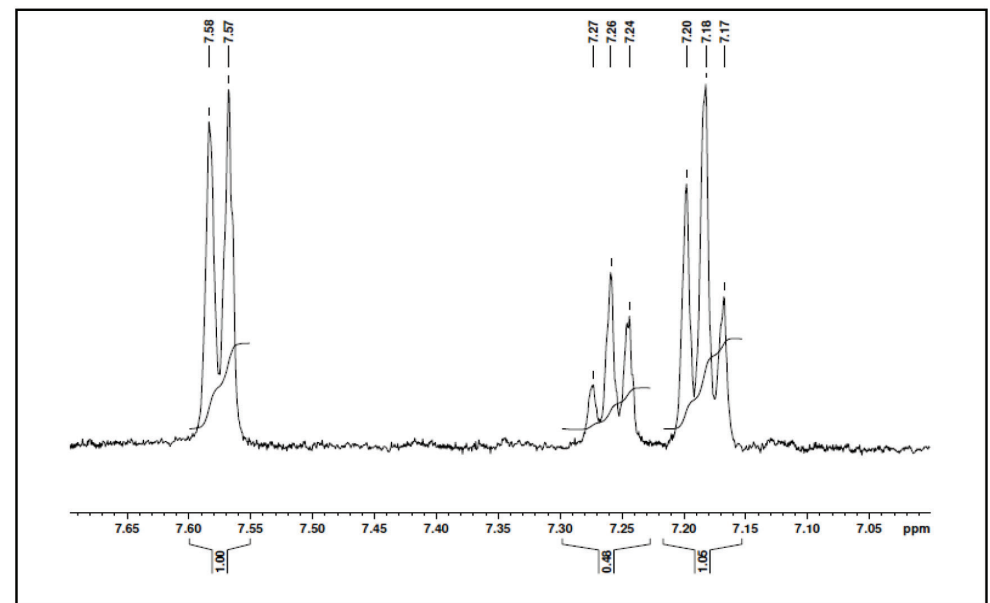

(i)

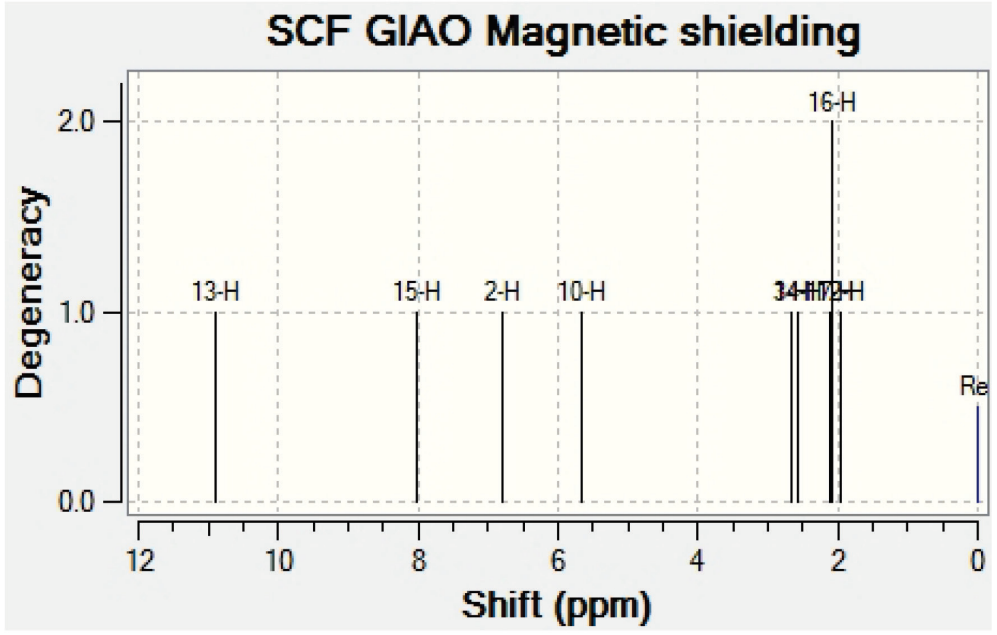

(ii)

Figure 8: ${ }^{1} \mathrm{H}$ NMR spectrum of GUOM along with theoretical spectrum. 


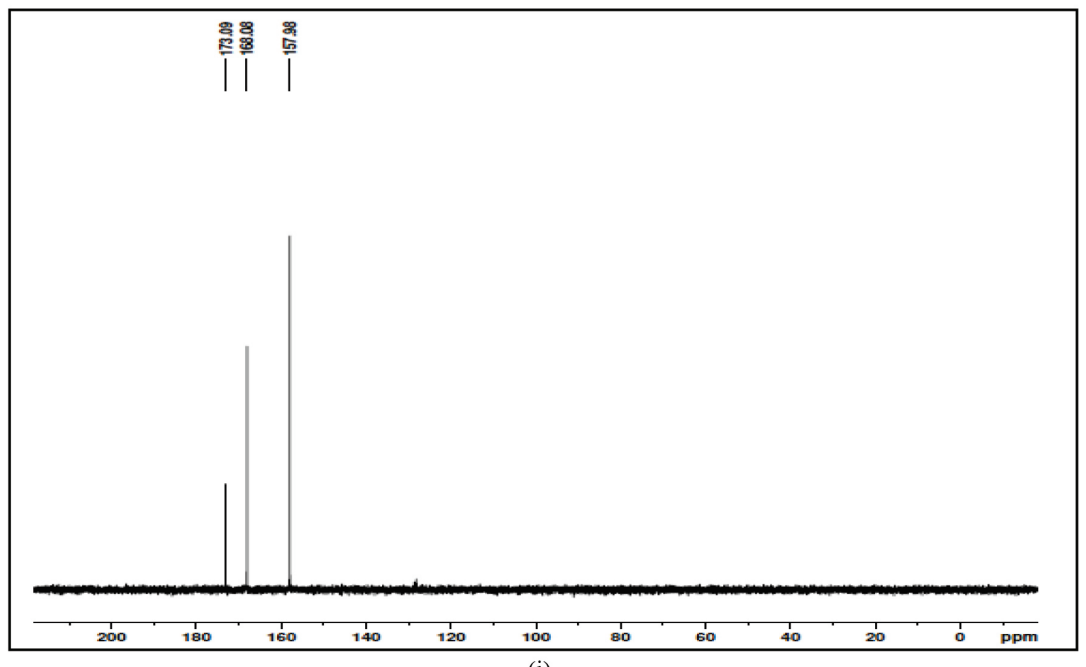

(i)

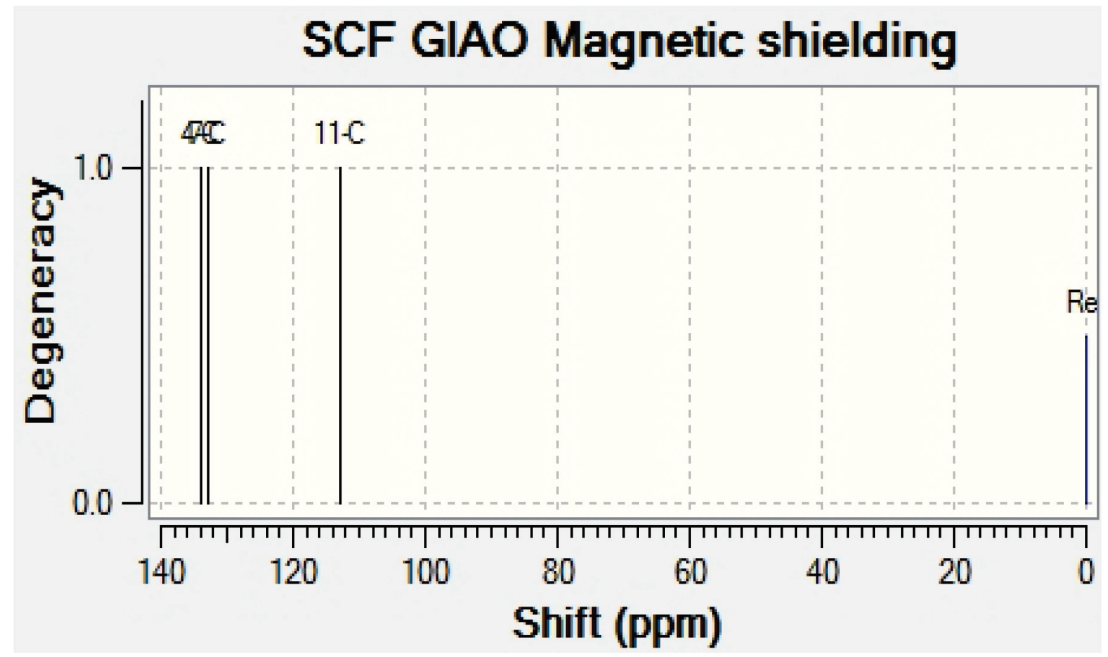

(ii)

Figure 9: ${ }^{13} \mathrm{C}$ NMR spectrum of GUOM along with theoretical spectrum. 


\section{OPTICAL STUDY}

In order to study the optical absorption characteristics of the grown crystal, clear single crystal of thickness about $2 \mathrm{~mm}$ is used for this study. The presence of auxochromes namely amino group and carboxyl group makes it transparent in the UV-Vis-NIR region (Figure 10). In the UV-Vis region with high extinction coefficients, all molecules allow strong $\pi-\pi^{*}, \sigma-\sigma^{*}$ and $n-\pi^{*}$ transitions. ${ }^{25,26}$ The solvent effect is studied using the TD-DFT method for the B3LYP/6-311G basis set. The experimental and simulated (in gas phase and water) UV-Vis spectra of the title compound are presented in Figure 8 and Figure 9. Position and absorbance of the experimental peaks together with the calculated excitation energies, oscillator strength $(f)$, wavelength $(\lambda)$ and spectral assignments are listed in Table 7 . The computed results show that the first excited state originates from the HOMO to LUMO transition that corresponds to the $\lambda_{\max }$ absorption band in the UV-Vis spectrum. From the table, the first allowed transition is calculated at $319 \mathrm{~nm}$ in the gas phase with oscillator strength of 0.0004 . The next strong transitions occur at $271.44 \mathrm{~nm}$ with oscillator strength of 0.0037 in gas phase and at $227.54 \mathrm{~nm}$ with oscillator strength of 0.0111 in the gas phase. The three absorption peaks are identified in water at $310.26 \mathrm{~nm}, 267.37 \mathrm{~nm}$ and $243.93 \mathrm{~nm}$ with the oscillator strength $0.0003,0.0039$ and 0.0022 , respectively.

The experimental absorption spectrum shows a strong peak at $199 \mathrm{~nm}$ corresponding to the calculated wavelength of $227 \mathrm{~nm}$ in gas phase, which is attributed to the presence of carboxyl and amino group in the title compound. 


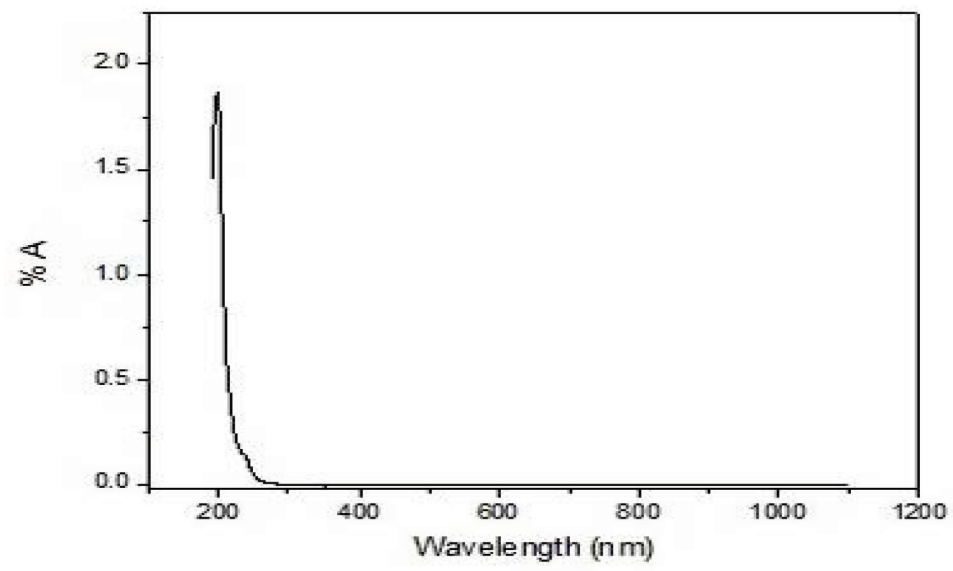

(a)

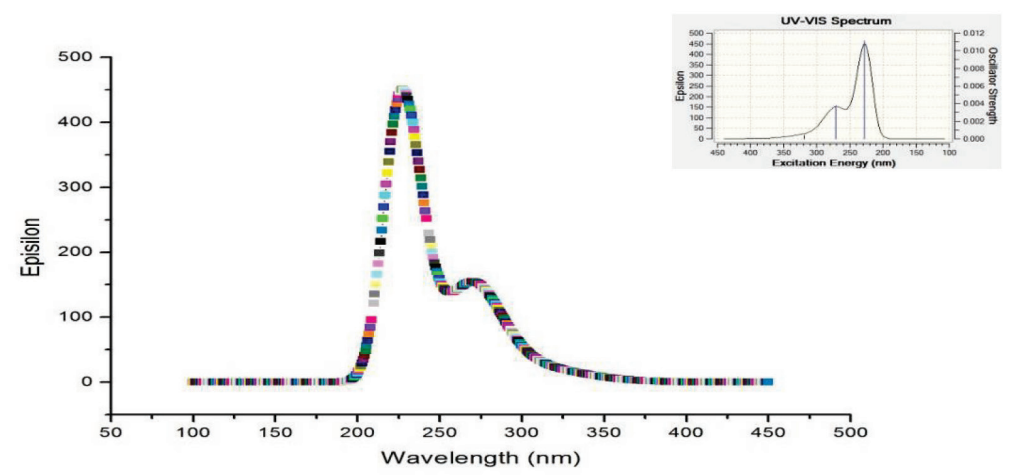

(b)

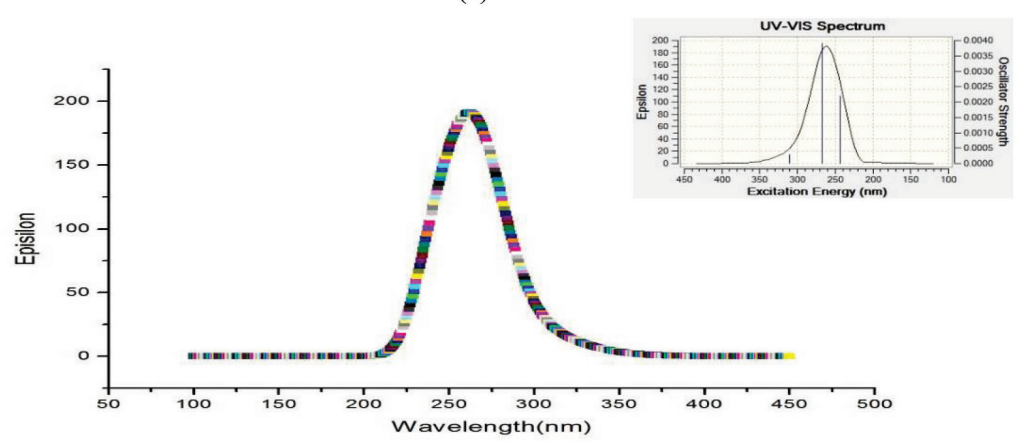

(c)

Figure 10: Illustration of (a) UV-vis spectrum of GUOM, (b) simulated UV-vis spectrum of GUOM in gas, (c) simulated UV-vis absorption spectrum of GUOM in water. 
Table 7: Calculated and experimental wavelengths of GUOM using TD-DFT method at B3LYP/6-311G level.

\begin{tabular}{|c|c|c|c|c|c|}
\hline Excitations & $\begin{array}{l}\text { Extinction } \\
\text { co- } \\
\text { efficient }\end{array}$ & $\begin{array}{l}\text { Excitation } \\
\text { energy } \\
(\mathrm{eV})\end{array}$ & $\begin{array}{l}\text { Wavelength } \\
(\mathrm{nm})\end{array}$ & $\begin{array}{l}\text { Oscillator } \\
\text { (f) }\end{array}$ & $\begin{array}{l}\text { Experimental } \\
\text { wavelength } \\
(\mathrm{nm})\end{array}$ \\
\hline \multicolumn{6}{|l|}{ Gas Phase } \\
\hline Excited State 1 & Singlet & \multirow{2}{*}{3.8853} & \multirow{2}{*}{319.11} & \multirow{2}{*}{0.0004} & \multirow{10}{*}{199} \\
\hline $\mathrm{HOMO} \rightarrow \mathrm{LUMO}$ & 0.69554 & & & & \\
\hline Excited State 2 & Singlet-A & & & & \\
\hline HOMO-2 $\rightarrow$ LUMO+1 & 0.35209 & 4.5677 & 271.44 & 0.0037 & \\
\hline HOMO-1 $\rightarrow$ LUMO+1 & 0.59498 & & & & \\
\hline Excited State 3 & Singlet-A & \multirow{5}{*}{5.4489} & \multirow{5}{*}{227.54} & \multirow{5}{*}{0.0111} & \\
\hline HOMO-6 $\rightarrow$ LUMO+1 & 0.43442 & & & & \\
\hline HOMO-4 $\rightarrow$ LUMO & 0.11232 & & & & \\
\hline HOMO-3 $\rightarrow$ LUMO & -0.33585 & & & & \\
\hline HOMO-2 $\rightarrow$ LUMO & 0.30519 & & & & \\
\hline \multicolumn{6}{|l|}{ Water } \\
\hline Excited State 1 & Singlet-A & \multirow{4}{*}{3.9961} & \multirow{4}{*}{310.26} & \multirow{3}{*}{0.0003} & \multirow{10}{*}{-} \\
\hline HOMO-2 $\rightarrow$ LUMO & -0.10410 & & & & \\
\hline $\mathrm{HOMO} \rightarrow$ LUMO & 0.69276 & & & & \\
\hline Excited State 2 & Singlet-A & & & & \\
\hline HOMO-4 $\rightarrow$ LUMO & 0.18430 & \multirow{3}{*}{4.6373} & \multirow{3}{*}{267.37} & \multirow{3}{*}{0.0039} & \\
\hline HOMO-3 $\rightarrow$ LUMO & 0.14426 & & & & \\
\hline HOMO-2 $\rightarrow$ LUMO & 0.64394 & & & & \\
\hline Excited State 3 & Singlet-A & \multirow{3}{*}{5.0827} & \multirow{3}{*}{243.93} & \multirow{3}{*}{0.0022} & \\
\hline HOMO-4 $\rightarrow$ LUMO & -0.18339 & & & & \\
\hline HOMO-1 $\rightarrow$ LUMO & 0.67330 & & & & \\
\hline
\end{tabular}

\section{THERMAL ANALYSIS}

To explore the thermal stability and the ease of formation of the crystal from the starting material, thermal decomposition studies are carried out. As evident from the TGA-DTA curves (Figure 11, Table 8), GUOM crystal shows a weight loss of approximately $57.5 \%$ (calc. $57.8 \%$ ) up to $276^{\circ} \mathrm{C}$. This sharp weight loss corresponds to the decomposition of the organic oxalic acid moiety. The DTA curves of the crystal shows a strong endothermic peak supporting this interpretation. 
After liberation of the oxalic acid the material subsequently decomposes drastically and then gradually upto $525^{\circ} \mathrm{C}$, leaving small amount of carbon residue. This stage of decomposition occurs between the temperature ranges of $276^{\circ} \mathrm{C}$ and $525^{\circ} \mathrm{C}$ with a weight loss of $38.1 \%$ (calc. $38.7 \%$ ). This second step of decomposition is due to the liberation of the triaminomethane group attached to the organic group. This is authenticated by the two endothermic peaks observed at $332^{\circ} \mathrm{C}$ and $451{ }^{\circ} \mathrm{C}$. The endothermic peak appeared at $332^{\circ} \mathrm{C}$ belongs to melting of triaminomethane and the same at $451{ }^{\circ} \mathrm{C}$ is endorsed to its burning. To evaluate the structural stability properties of the GUOM crystal, kinetic aspects of the thermal decomposition are studied. By employing the Coats-Redfern and Horowitz-Metzger relations on the decomposition steps of thermogram.

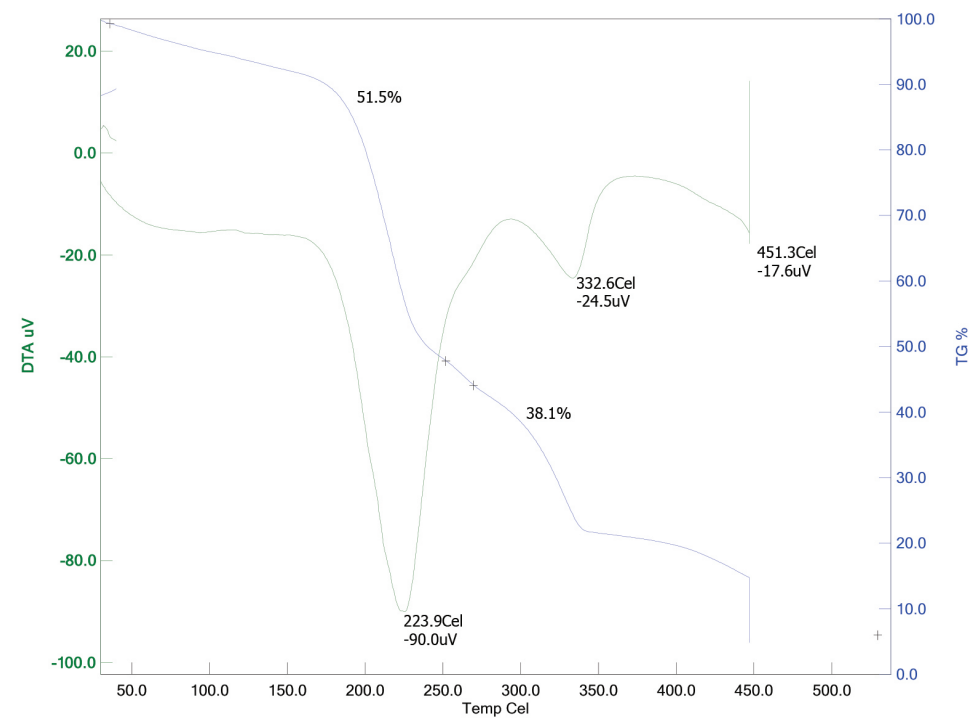

Figure 11: TG/DTA of GUOM.

Table 8: Thermal analyses information of GUOM crystal.

\begin{tabular}{|c|c|c|c|c|c|c|c|}
\hline \multirow{2}{*}{$\begin{array}{l}\text { Sl. } \\
\text { No. }\end{array}$} & \multirow{2}{*}{$\begin{array}{l}\text { TGA } \\
\text { temp. } \\
\text { range } \\
\left({ }^{\circ} \mathrm{C}\right)\end{array}$} & \multicolumn{2}{|c|}{ Weight loss } & \multirow{2}{*}{$\begin{array}{l}\text { DTA } \\
\text { temp. } \\
\text { range } \\
\left({ }^{\circ} \mathrm{C}\right)\end{array}$} & \multirow{2}{*}{$\begin{array}{l}\text { DTA } \\
\text { peak } \\
\left({ }^{\circ} \mathrm{C}\right)\end{array}$} & \multirow{2}{*}{ DTA nature } & \multirow{2}{*}{ Inference } \\
\hline & & (obs.) & (calc.) & & & & \\
\hline 1 & $20-273$ & 57.5 & 57.8 & $160-273$ & 223.9 & Endothermic & - oxalic acid \\
\hline \multirow{2}{*}{2} & \multirow{2}{*}{$273-580$} & \multirow{2}{*}{38.1} & \multirow{2}{*}{38.7} & $273-360$ & 332.6 & Endothermic & Melting \\
\hline & & & & $435-480$ & 451.3 & Endothermic & - triaminomethane \\
\hline
\end{tabular}

$\ln \left[\frac{1-(1-\alpha)^{1-n}}{(1-n) r^{2}}\right]=\frac{M}{T}+\mathrm{B}$ for $\mathrm{n} \neq 1$ 
$\ln \left[\frac{1-(1-\alpha)}{r^{2}}\right]=\frac{M}{T}+\mathrm{B}$ for $\mathrm{n}=1$

Here, $\mathrm{M}=-\mathrm{E}^{*} / \mathrm{R}$ and $\mathrm{B}=\ln \mathrm{AR} / ; \mathrm{E}^{*} \Phi ; \mathrm{E}^{*}, \mathrm{R}, \mathrm{A}$ and are the heat of activation, the universal gas constant, pre-exponential factor and heating rate, respectively.

$$
\begin{aligned}
& \ln \left[\frac{(1-(1-\alpha)) 1-\mathrm{n}}{1-\mathrm{n}}\right]=\ln \frac{Z R T_{S}^{2}}{\Phi E}-\frac{E}{R T_{S}}+\frac{\mathrm{E} \theta}{\mathrm{RT}_{\mathrm{S}}^{2}} \text { for } \mathrm{n} \neq 1 \\
& \ln [-\ln (1-\alpha)]=\frac{\mathrm{E} \theta}{\mathrm{RT}_{\mathrm{S}}^{2}} \text { for } \mathrm{n}=1
\end{aligned}
$$

where $\mathrm{q}=\mathrm{T}-\mathrm{T}_{\mathrm{S}}, \mathrm{T}$ is the temperature at the DTG peak. The correlation coefficient $r$ is computed using the least squares method for Equations 14, 15, 16 and 17. Linear curves are drawn for different values of $n$ ranging from 0 to 2 . The value of $\mathrm{n}$, which gave the best fit, is chosen as the order parameter for the decomposition stage of interest. The other kinetic parameters such as $\Delta \mathrm{H}^{*}$ and $\Delta \mathrm{S}^{*}$ are computed using the relations.

$$
\begin{aligned}
& \Delta \mathrm{H}^{*}=\mathrm{E}^{*}-\mathrm{RT} \\
& \Delta \mathrm{S}^{*}=\mathrm{R}\left[\ln (\mathrm{Ah} / \mathrm{kT})^{-1}\right] \\
& \Delta \mathrm{G}^{*}=\Delta \mathrm{H}^{*}-\mathrm{T} \Delta \mathrm{S}^{*}
\end{aligned}
$$

where $\mathrm{k}$ is the Boltzmann's constant and $\mathrm{h}$ is the Planck's constant.

The kinetics parameters calculated using Coats-Redfern and Horowitz-Metzger methods are given in Table 9. ${ }^{27,28}$ The following remarks can be made from the results:

1. The entropy $\left(\Delta \mathrm{S}^{*}\right)$ of the degradation steps is negative indicating that the final state (i.e., the crystal) is more ordered than the reactants. This implies that the crystal is more stable than its reactants. ${ }^{28}$

2. The values of the activation energy $\mathrm{E}^{*}$ increases significantly with $\mathrm{T} \Delta \mathrm{S}^{*}$, which supersede the values of $\Delta \mathrm{H}^{*}$. Increasing values of $\Delta \mathrm{G}^{*}$ for the decomposition step infer that the rate of removal of a liberating group will be lower than that of the precedent group. This may be attributed to the structural rigidity of the remaining portion of the crystal after the expulsion of one and more groups. The remaining groups require more $\mathrm{T} \Delta \mathrm{S}^{*}$ energy for its rearrangement before undergoing any compositional change. 
3. There is a conspicuous gap in the values of the activation energy $\left(\mathrm{E}^{*}\right)$ and the enthalpy of activation $\left(\Delta \mathrm{H}^{*}\right)$ of volatilisation of the decomposition stage. This may be attributed to the dense packing of GUOM. However, the $\Delta \mathrm{H}^{*}$ is compensated by the entropy, leading to positive value for the $\Delta \mathrm{G}^{*}$. The positive $\Delta \mathrm{G}$, values denotes the nonspontaneous nature of decomposition.

Table 9: Kinetic parameters for GUOM by different TG methods.

\begin{tabular}{lll}
\hline Parameter & Coats-Redfern & Horowitz-Metzger \\
\hline $\mathrm{E}$ & $3.52 \times 10^{4}$ & $3.64 \times 10^{4}$ \\
$\mathrm{~A}$ & $4.68 \times 10^{1}$ & $4.46 \times 10^{1}$ \\
$\Delta \mathrm{S}$ & $-1.46 \times 10^{2}$ & $-1.53 \times 10^{2}$ \\
$\Delta \mathrm{H}$ & $4.27 \times 10^{4}$ & $4.35 \times 10^{4}$ \\
$\Delta \mathrm{G}$ & $2.23 \times 10^{5}$ & $2.35 \times 10^{5}$ \\
\hline
\end{tabular}

\section{ANTIMICROBIAL ACTIVITY ANALYSIS}

The test organisms used in the study are E. coli, Proteus, Staphylococcus, Klebsiella, Pseudomonas and Streptococcus species. The cultures are maintained at $4^{\circ} \mathrm{C}$ on Nutrient agar (HiMedia) slants. The antibacterial analysis is performed by agar well diffusion method. $20 \mathrm{ml}$ of sterile Muller Hinton agar (Hi Media) is poured in sterile Petri dishes, which are allowed to solidify and are used for the test. $10 \mathrm{ml}$ of sterile, Muller Hinton agar medium (seed agar) is seeded with organism (about $0.2 \mathrm{ml}$ according to $0.5 \mathrm{McFarland}$ 's standard), in semi hot conditions and is poured uniformly on the base agar. $8 \mathrm{~mm}$ bores are made, each equidistant from one another on the medium using sterile borer and $100 \mu 1$ of the different sample preparation are added to respective bore. The plates are incubated at $37^{\circ} \mathrm{C}$ for $24 \mathrm{~h}$ and zone of inhibition is measured. A reference standard of streptomycin $(100 \mu \mathrm{g} /$ $\mathrm{ml}$ ) is also used to compare with the results obtained for the present sample under study. For each test, three replicates are performed. The antimicrobial activity of the given sample against the above micro-organisms has been recorded as per the zone of inhibition formation.

The result indicate that guanidinium carbonate and GUOM are more effective for Klebsiella pneumoniae when compared with other organisms such as Staphylococcus, E.coli, Streptococcus, Staphylococcus and Pseudomonas. The antimicrobial observations are summarised in Table 10. Figure 12 shows the antimicrobial activity of GUOM against microorganisms as per zone of inhibition formation. 
Table 10: Antibacterial activity of different chemical compound preparation against pathogenic bacterial strains.

\begin{tabular}{lccc}
\hline \multirow{2}{*}{ Name of bacteria } & \multicolumn{3}{c}{ Mean zone of inhibition in diameter (cm) } \\
\cline { 2 - 4 } & GC & GUOM & STD \\
\hline E. coli & 2.2 & 1.6 & 2.1 \\
Pseudomonas aeruginosa & - & - & 1.6 \\
Staphylococcus aureus & - & - & 1.7 \\
Klebsiella pneumoniae & 3.7 & 2.2 & 2.4 \\
Proteus vulgaris & - & - & 1.9 \\
Streptococcus pneumoniae & 3.1 & 1.7 & 2.0 \\
\hline
\end{tabular}

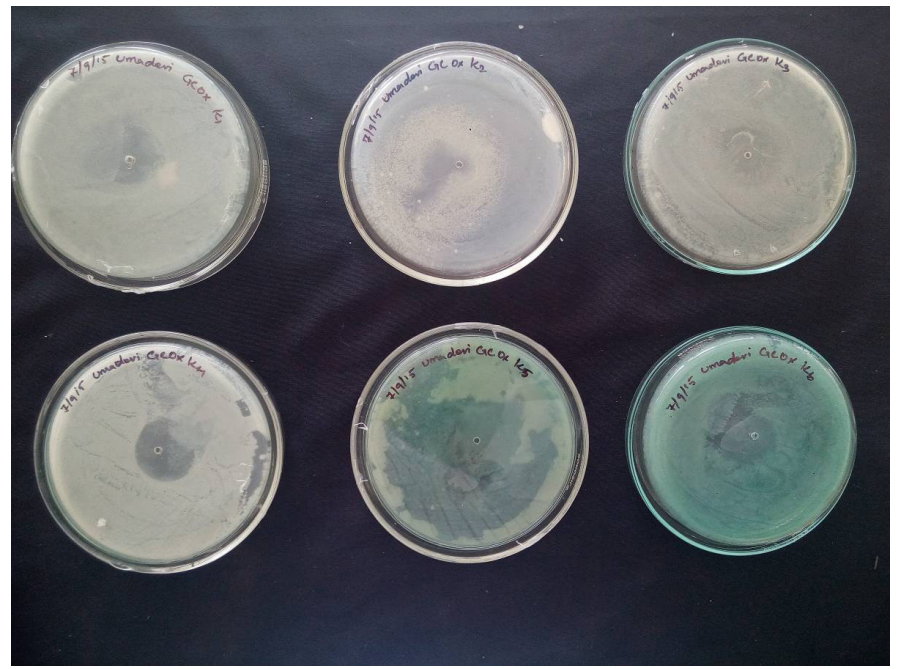

Figure 12: The antimicrobial activity of GUOM against microorganisms as per the zone of inhibition formation.

\section{CONCLUSION}

Employing solution method, the crystals of GUOM is grown. The crystal structure of GUOM is monoclinic as determined by single crystal X-ray diffraction analysis. The theoretically predicted geometric parameters are in agreement with the experimental crystal structural data. A small value of HOMO-LUMO energy gap serves as evidence for intramolecular charge transfer. The first hyperpolarisability $(\beta)$ of the GUOM molecule has been numerically calculated and compared with the earlier measurements in other organic systems. The FTIR spectrum of GUOM has 
also been recorded and compared with the theoretical data. The TG/DTA results reveal the thermal stability. The antimicrobial activity shows that GUOM is more effective for Klebsiella pneumoniae.

\section{ACKNOWLEDGEMENTS}

Author T. Uma Devi thanks the University Grants Commission (UGC) for the fund provided for the minor research project - MRP 5164/14 (SERO/UGC).

\section{REFERENCES}

1. Adams, J. M. \& Small, R. W. H. (1974). The crystal structure of guanidinium carbonate. Acta Cryst. B, 30, 2191-2193, https://doi.org/10.1107/ S0567740874006716.

2. Todorova, T., Kröcher, O. \& Delley, B. (2009). DFT study of structural and vibrational properties of guanidinium derivatives. J. Mol. Str. Theochem., 907, 16-21, https://doi.org/10.1016/j.theochem.2009.04.017.

3. Kröcher, O., Elsener, M. \& Jacob, E. (2009). A model gas study of ammonium formate, methanamide and guanidinium formate as alternative ammonia precursor compounds for the selective catalytic reduction of nitrogen oxides in diesel exhaust gas. Appl. Catal. B, 88, 66-82, https://doi.org/10.1016/j. apcatb.2008.09.027.

4. Otvos, J. W. \& Edsall, J. T. (1939). Raman spectra of deuterium substituted guanidine and urea. J. Chem. Phys., 7, 632, http://dx.doi. org/10.1063/1.1750506.

5. Angell, C. L. et al. (1957). The infra-red spectrum, structure, and normal vibrations of the guanidinium ion. Trans. Faraday Soc., 53, 589, https://doi. org/10.1039/tf9575300589.

6. Bonner, O. D. \& Jordan, C. F. (1976). The infrared and Raman spectra of guanidinium salts. Spectrochim. Acta, 32, 1243, https://doi.org/10.1016/05848539(76)80316-9

7. Fun, H. N. et al. (2011). Bis(4-fluoroanilinium) sulfate. Acta Cryst., E67, o2408-o2417, https://doi.org/10.1107/S1600536811033137

8. Herbstein, F. H. (1971). Crystalline $\pi$-molecular compounds. In (Ed.) Dunitz, J. D. \& Ibers, J. A. Perspective in structural chemistry. New York: Wiley and Sons, 166-395. 
9. Ward, M. D. et al. (1989). Electrostatic structural enforcement in lowdimensional solids: Synthesis, structure, and electronic properties of polycationic ruthenium complexes with polycyanoanions. J. Am. Chem. Soc., 111, 1719-1732. https://doi.org/10.1021/ja00187a025.

10. Fagan, P. J., Ward, M. D. \& Calabrese, J. C. (1989). Molecular engineering of solid-state materials: Organometallic building blocks. J. Am. Chem. Soc., 1698-1719, https://doi.org/10.1021/ja00187a024.

11. Orner, B. P. \& Hamilton, A. D. (2001). The guanidinium group in molecular recognition: Design and synthetic approaches. J. Incl. Phenom. Macrocycl. Chem., 41, 141-147, https://doi.org/10.1023/A:1014433715641

12. Gobbi, A. \& Frenking, G. (1993). Y-Conjugated compounds: The equilibrium geometries and electronic structures of guanidine, guanidinium cation, urea, and 1,1-diaminoethylene. J. Am. Chem. Soc., 115(6), 2362-2372, https://doi. org/10.1021/ja00059a035

13. Zyss, J. et al. (1993). Synthesis and crystal structure of guanidinium L-monohydrogentartrate: Encapsulation of an optically nonlinear octupolar cation. Acta Crystallogr. B, 49, 334-342, https://doi.org/10.1107/ S010876819200839

14. Russell, V. A., Etter, M. C. \& Ward, M. D. (1994). Guanidinium parasubstituted benzenesulfonates: Competitive hydrogen bonding in layered structures and the design of nonlinear optical materials. Chem. Mater., 6, 1206-1217. https://doi.org/10.1021/cm00044a019

15. Arumanayagam, T. \& Murugakoothan, O. (2011). Studies on optical and mechanical properties of new organic NLO crystal: Guanidinium 4-aminobenzoate (GuAB). Mater. Lett., 65, 2748-2750. https://doi. org/10.1016/j.matlet.2011.05.081

16. Dhavamurthy, M., Peramaiyan, G. \& Mohan, R. (2014). Synthesis, growth, structural, optical, thermal, dielectric and mechanical studies of an organic guanidinium p-nitrophenolatecrystal. Cryst. Gro., 399, 13-18, https://doi. org/10.1016/j.jcrysgro.2014.04.013.

17. Sajan, D. et al. (2004). NIR-FT Raman and infrared spectra and ab initio computations of glycinium oxalate. Spectrochim. Acta A, 60, 173-180. https://doi.org/10.1016/S1386-1425(03)00193-8.

18. Adams, J. M. (1978). The crystal structure of guanidinium hydrogen oxalate monohydrate. Acta Cryst., B34, 1218-1220, https://doi.org/10.1107/ S0567740878005245

19. Andrews, L. C. et al. (1979). An improved crystal and molecular structure of guanidinium hydrogen oxalate monohydrate, $\mathrm{C}\left(\mathrm{NH}_{2}\right)_{3} \mathrm{HC}_{2} \mathrm{O}_{4} \cdot \mathrm{H}_{2} \mathrm{O}$. J. Cryst. Mol. Struct., 9, 163-171, https://doi.org/10.1007/BF01262808. 
20. Lampert, H., Mikenda, W. \& Karpten, A. (1997). Molecular geometries and vibrational spectra of phenol, benzaldehyde, and salicylaldehyde: Experimental versus quantum chemical data. J. Phys. Chem., 101, 22542263. https://doi.org/10.1021/jp962933g.

21. Zaleśny, R. et al. (2009). Static electronic and vibrational first hyperpolarizability of meta-dinitrobenzene as studied by quantum chemical calculations. J. Mol. Struct. Theochem., 907, 46-50, https://doi.org/10.1016/j. theochem.2009.04.011.

22. Pearson, R. G. (1986). Absolute electronegativity and hardness correlated with molecular orbital theory. Proc. Natl. Acad. Sci. (USA), 83, 8440-8441, https://doi.org/10.1073/pnas.83.22.8440.

23. Lee, C., Yang, W. \& Parr, G. R. (1988). Development of the Colle-Salvetti correlation-energy formula into a functional of the electron density. Phys. Rev. B Condens. Matter, 37, 785-789, https://doi.org/10.1103/PhysRevB.37.785.

24. Parr, R. G., Szentpaly, L. V. \& Liu, S. (1999). Electrophilicity index. J. Am. Chem. Soc., 121, 1922-1924, https://doi.org/10.1021/ja983494x.

25. Parthasarathi, R. et al. (2003). Toxicity analysis of benzidine through chemical reactivity and selectivity profiles: A DFT approach. Int. Electron J. Mol. Des., 2, 798-813.

26. Kleinman, D. A. (1962). Nonlinear dielectric polarization in optical media. Phys. Rev., 126, 1977-1979, https://doi.org/10.1103/PhysRev.126.1977.

27. Coats, A. W. \& Redfern, J. P. (1964). Kinetic parameters from thermogravimetric data. Nature, 201,68-69, https://doi.org/10.1038/201068a0

28. Horowitz, H. \& Metzger, G. (1963). A new analysis of thermogravimetric traces. Anal. Chem., 35, 1464-1468. https://doi.org/10.1021/ac60203a013. 